\title{
A case of seminal vesicle cyst associated with ipsilateral renal agenesis diagnosed during an investigation of urinary incontinence
}

\author{
Burhan Coşkun ${ }^{1}$, Ayhan Dalkılıç², Nurettin Cem Sönmez², Serdar Arısan², Yılmaz Ofluoğlu², Erbil Ergenekon²
}

${ }^{1}$ Clinic of Urology, İnegöl Public Hospital, Bursa, Turkey

${ }^{2}$ Clinic of Urology, Şişli Etfal Training and Research Hospital, Istanbul, Turkey

Submitted:

16.08.2011

Accepted:

10.01.2012

\section{Correspondence:}

Burhan Coşkun

Doburca Cad. Başak Sitesi C Blok,

No:4, Osmangazi 16090

Bursa, Turkey

Phone: +90 5336460323

E-mail:

drburhancoskun@yahoo.co.uk

(C) Copyright 2013 by Turkish Association of Urology

Available online at www.turkishjournalofurology.com

\begin{abstract}
Seminal vesicle cysts are rare and usually associated with ipsilateral renal agenesis. The diagnosis of seminal vesicle cysts may be delayed or missed because of the non-specific symptoms of this condition. In this study, we aimed to discuss the diagnosis and treatment of a left seminal vesicle cyst that was associated ipsilateral agenesis in a 24-year-old patient who presented to our outpatient department with urinary incontinence. Ultrasonography and magnetic resonance imaging revealed a seminal vesicle cyst measuring $40 \times 45 \mathrm{~mm}$ in diameter. Although the patient's symptoms were relieved with cyst aspiration via transrectal ultrasonography, the symptoms recurred 6 months later.
\end{abstract}

Key words: Ipsilateral renal agenesis; seminal vesicle cyst; urgency incontinence.

\section{Introduction}

Congenital seminal vesicle cysts (SVCs) are rare and usually associated with ipsilateral renal agenesis. ${ }^{[1]}$ SVC diagnosis may be delayed or missed because of the non-specific symptoms of this condition. In this article, we present a case of SVC associated with ipsilateral renal agenesis.

\section{Case presentation}

A 24-year-old male patient presented to our outpatient department with urge incontinence. He also had perianal pain, postcoital discomfort and hemospermia. Previously, he had been diagnosed with chronic prostatitis and prescribed several antibiotics. At that time, however, his symptoms were not relieved. Physical examinations of the abdomen and prostate were normal. Abdominal ultrasonography (USG) revealed a hypoechoic and welldefined mass that appeared cyst-like, and the patient's left kidney was missing. Abdominal magnetic resonance imaging (MRI) revealed a multiple cyst formation, which was hyperintense on T1- and T2-weiged sequences, without contrast enhancement at the seminal vesicle location and with a maximum dimension of $40 \times 45 \mathrm{~mm}$ (Figures 1,2). The MRI also confirmed left renal agenesis (Figure 3). We decided to perform a cystoscopy to rule out other bladder-related pathologies; according to the cystoscopy, the hemitrigone was missing, with a protrusion image on the left side. The patient underwent trans-rectal ultrasonography (TRUSG), and concomitant cyst aspiration was performed; the aspirate contained spermatozoa. The patient's symptoms were relieved during the postoperative period, without any complication. At the 6-month follow-up, his symptoms recurred, and open cyst resection was recommended; however, the patient requested follow-up without surgical intervention.

\section{Discussion}

The embryogenic developments of urinary and reproductive systems are closely related. The ureteral bud originates from the caudal end of the mesonephric duct at approximately gestational week 4 , and proper interaction between the mesonephric duct and urogenital sinus results in the correct anatomical placement of the ureteral orifice on the bladder trigone. The ureteral bud also grows cranially towards the metanephrogenic blastema to stimulate renal development. In the $13^{\text {th }}$ week of gestation, the seminal vesicles proliferate from the mesoneph- 


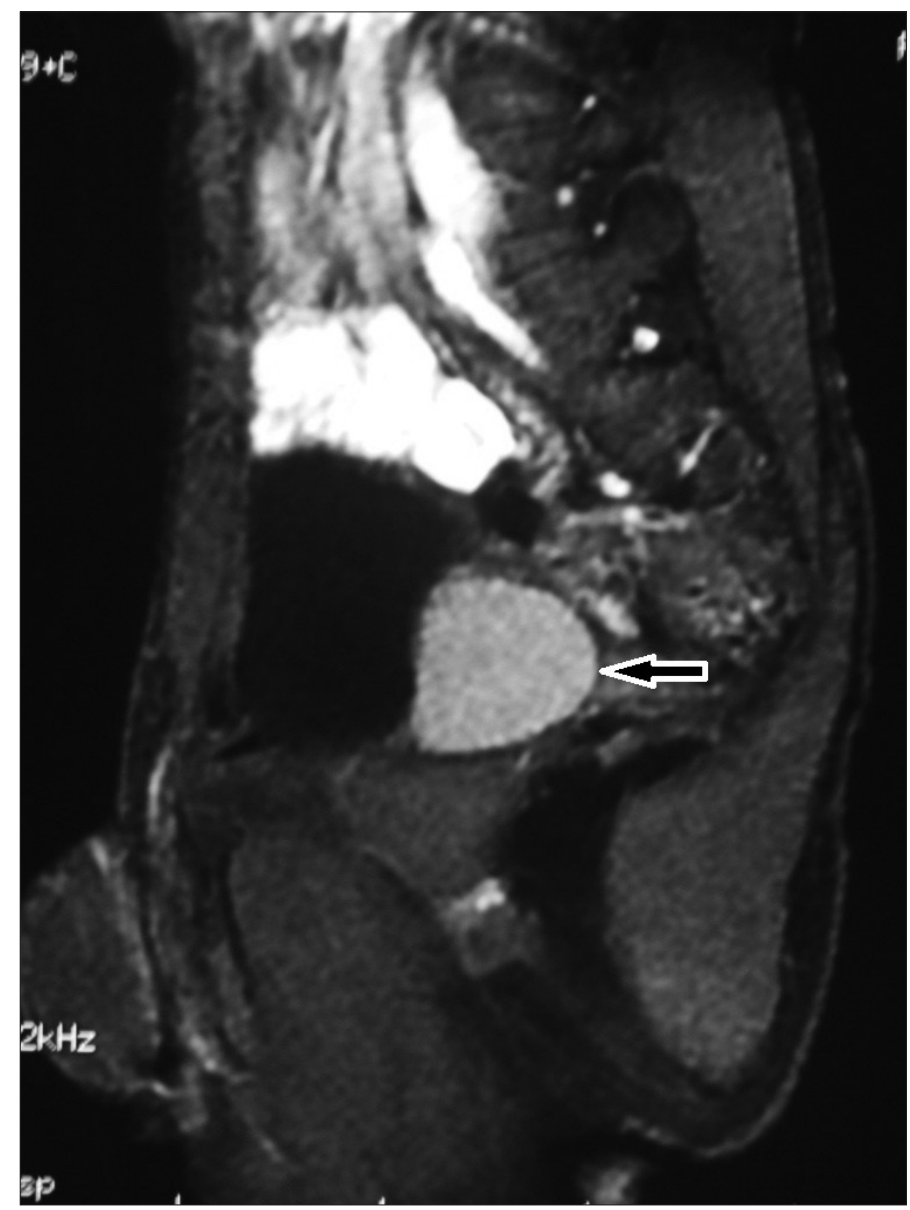

Figure 1. Arrow shows seminal vesicle cyst as a hyperintense image on an MRI T1 sequence

ric duct in a location more caudal than the ureteral bud. The vas deferens, ejaculatory duct and lower two-thirds of the epididymis also arise from mesonephric duct system. ${ }^{[2]}$ The maldevelopment of the distal mesonephric duct and faulty ureteral budding may lead to renal agenesis or dysplasia, and atresia of the ejaculatory duct may cause obstruction and cystic dilatation of the seminal vesicle. ${ }^{[3]}$

SVCs measuring $<5 \mathrm{~cm}$ in diameter are usually asymptomatic. ${ }^{[3,4]}$ Symptomatic SVCs usually occur in the second to fourth decades of life, as the result of accumulated seminal fluid in the seminal vesicle caused by a blocked ejaculatory duct. [1,5] Symptoms generally develop because of irritation of the adjacent organs by the enlarged and inflamed cyst. Urgency, frequency, dysuria and hematuria may be the result of bladder irritation, and cyst distention may cause perinealperianal or suprapubic pain, hemospermia, post-coital discomfort or painful defecation.$^{[1,2]}$ In our patient, the maximum dimension of the cyst was $40 \times 45 \mathrm{~mm}$, which was slightly smaller for a symptomatic cyst. The patient also experienced incontinence, which is rarely mentioned in the literature as a symptom.

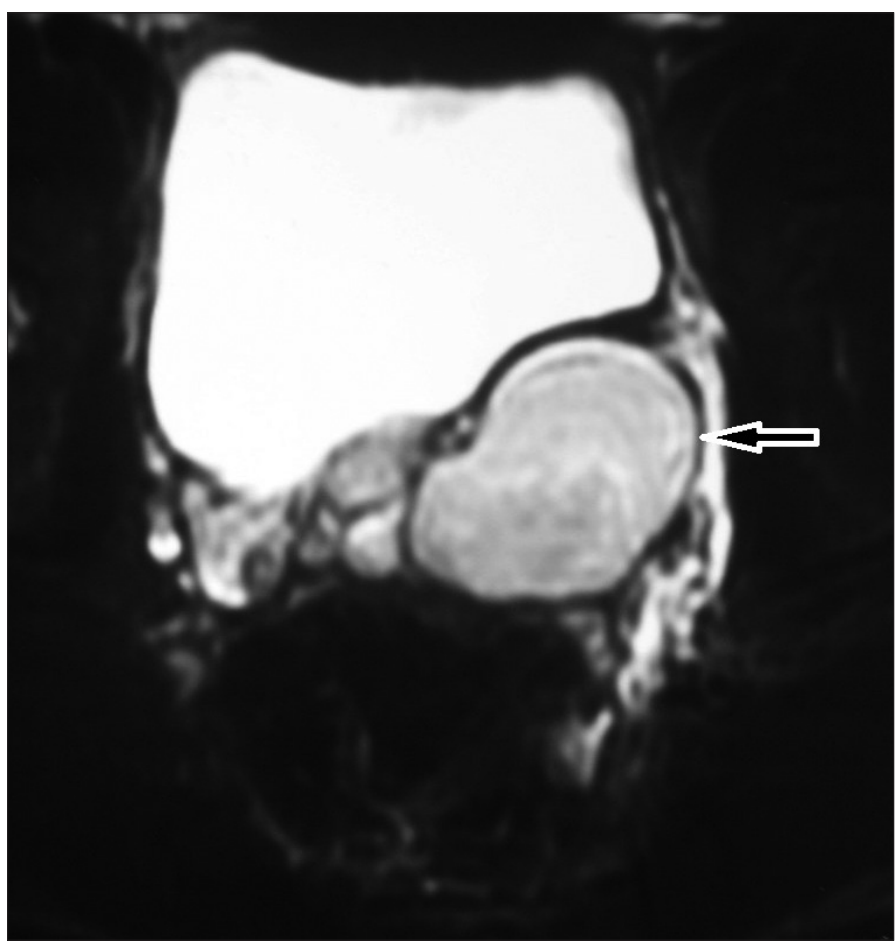

Figure 2. Arrow shows a seminal vesicle cyst as a hyperintense image on an MRI T2 sequence

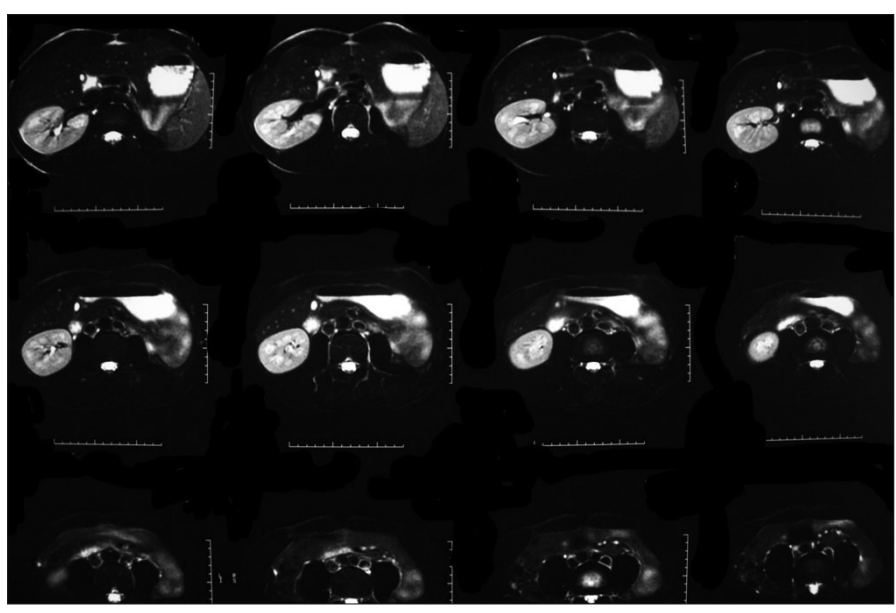

Figure 3. MRI shows the right kidney, however the left kidney was agenetic

A physical examination may reveal an indurate, tender epididymis and ductus deferens, or a palpable cystic mass associated with seminal vesicle upon a digital rectal examination. However, the physical examination may exhibit normal findings. ${ }^{[2]}$

Different types of imaging techniques, including excretory urography (EU), USG, computerized tomography (CT) and MRI can be utilized in a differential diagnosis of SVC from other cystic pelvic masses. ${ }^{[3]}$ As initial diagnostic tools, SG or 
TRUSG can confirm the cystic content of the pelvic masses and determine the sizes and locations. ${ }^{[2,3]} \mathrm{EU}$ can exhibit ipsilateral renal agenesis. However, SVC may not be clearly visualized with this method. CT shows SVC as a well-defined retrovesicular mass of water or near-water attenuation that arises from the seminal vesicle cephalic to the prostate gland. On MRI, SVC usually appears hypointense on a T1 sequence and hyperintense on a T2 sequence, without contrast enhancement. However, SVC may show hyperintensity on both sequences because of proteinaceous material or hemorrhage. ${ }^{[3]}$ MRI features, including multiplanar imaging capability, superior softtissue contrast, and lack of ionizing radiation, makes it a better tool to accurately define anatomic relationships when one is planning to excise a seminal vesicle cyst or if one is considering a difficult differential diagnosis. MRI may also reveal the opening of the associated ectopic ureter. ${ }^{[6]}$ After an initial diagnosis with USG, we preferred MRI, which successfully displayed the cystic nature of the pelvic mass and the relationship with the adjacent organs.

Cystoscopy may reveal an absent ipsilateral hemitrigone, intravesical cyst protrusion and any other anatomical abnormality of the bladder. ${ }^{[2]}$ In our patient, the left hemitrigone was missing, with an existing ipsilateral protrusion. Cystoscopy was also beneficial for ruling out any intravesical pathology.

The following factors should be considered in differential diagnoses: cystadenomas and papillary adenomas of the seminal vesicles, Müllerian duct cysts, diverticula of the ejaculatory ducts or ampulla of the vas, prostatic cysts, adenocarcinoma or sarcoma of the seminal vesicles, and secondary malignant tumors of the vesicles caused by adjacent organs and lymphomas. ${ }^{[7]}$

Asymptomatic patients who are incidentally diagnosed should be followed without intervention. In a symptomatic patient, several treatment modalities are available, such as transurethral unroofing, transurethral resection of the ejaculatory canal, transurethral endoscopic aspiration, transabdominal aspiration, transperineal aspiration, transrectal aspiration, open surgery, laparoscopic surgery and robotic surgery. ${ }^{[2,7,8]}$ We preferred to perform transrectal aspiration because the patient preferred not to undergo major surgery. Although transrectal aspiration is a simple and safe procedure, recurrence, the return of symptoms and infection are possible risk factors. Open surgery for SVC is challenging because of the deep location of the seminal vesicles in the retrovesical space and the needed large incision (with extensive bladder mobilization). Laparoscopy provides excellent intraoperative access and visualization with minimal postoperative morbidity. ${ }^{[2]}$ Similar good results are also achieved with robotic surgery, and features such as maneuverability and a shortened learning curve for the robotic systems make it an attractive method ${ }^{[8-10]}$

Conflict of Interest: No conflict of interest was declared by the authors.

\section{References}

1. van den Ouden D, Blom JH, Bangma C, de Spiegeleer AH. Diagnosis and management of seminal vesicle cysts associated with ipsilateral renal agenesis: a pooled analysis of 52 cases. Eur Urol 1998;33:433-40.

2. Cherullo EE, Meraney AM, Bernstein LH, Einstein DM, Thomas AJ, Gill IS. Laparoscopic management of congenital seminal veiscle cysts associated with ipsilateral renal agenesis. J Urol 2002;167:1263-7.

3. Livingston L, Larsen CR. Seminal vesicle cyst with ipsilateral renal agenesis. AJR Am J Roentgenol 2000;175:177-80

4. Savica V, Santoro D, Monardo P, Ciolino F, Maqistro A, Blandino A, et al. Seminal vesicle cysts with unilateral renal agenesis and contralateral ureteral stenosis in a $\beta$-thalassemic patient: an unknown association by incomplete development of the mesonephric duct. Urol Int 2007;79:367-70.

5. Patel B, Gujral S, Jefferson K, Evans S, Persad R. Seminal vesicle cysts and associated anomalies. BJU Int 2002;90:265-71.

6. Arora SS, Breiman RS, Webb EM, Westphalen AC, Yeh BM, Coakley FV. Congenital anomalies of the seminal vesicles. AJR Am J Roentgenol 2007;189:130-5.

7. Williams RD, Sandlow JI.Surgery of the seminal vesicles.Campbells Urology 7th ed. Philadelphia: W.B. Saunders;1998.p.3301

8. Moore CD, Erhard MJ, Dahm P. Robot-assisted excision of seminal vesicle cyst associated with ipsilateral agenesis. J Endourol 2007;21:776-9.

9. Carmack AJ, Siddiq FM, Leveillee RJ. Novel use of da Vinci Robotic Surgical System: removal of seminal vesicle cyst in previously dissected pelvis. Urology 2006;67:199.

10. Allaparthi S, Blute RD Jr. Novel application of da Vinci robotic system in patients of Zinners syndrome--case report and review of literature. Can J Urol 2010;17:5109-13. 